\title{
Measurement of social inequalities in health and use of health services among children in Northumberland
}

\author{
Richard Reading, Stephen Jarvis, Stan Openshaw
}

\begin{abstract}
Social inequalities in a variety of indicators of child health were measured using a 'small area' geographical method of social classification. Cross sectional analyses of routine child health information and of a population survey of the height of primary school children were used. Social classification was by census enumeration district of residence using the Townsend deprivation score.
\end{abstract}

Over 21000 children resident in Northumberland born between January 1985 and September 1990 , and 9930 children aged 5-8.6 years in Northumberland schools were studied.

The following differences between the most deprived $10 \%$ of areas and the most affluent $10 \%$ of areas were used as outcome measures: the proportion of birth weights less than $2800 \mathrm{~g}$; the proportion of births to teenage mothers; the proportion of 15 month old children not immunised against pertussis; the proportion of infants not screened at 6 weeks of age; the proportion of children not screened at 18 months of age; and the mean height of children in SD scores.

Between the most deprived and most affluent areas birth weights less than $2800 \mathrm{~g}$ varied from 18 to $11 \%$, the percentage of teenage mothers from 18 to $3 \%$, non-immunised children from 30 to $19 \%$, children not screened at 18 months from 21 to $14 \%$, and mean height from -0.2 SD scores to +0.1 SD scores. The area variation in screening at 6 weeks of age was less, but still poorer in deprived areas.

It is concluded that small area methods are effective in showing inequalities in child health, even in a rural area where such methods might be expected to perform less well. Social inequalities in all the aspects of child health measured remain evident.

(Arch Dis Child 1993; 68: 626-631)

Most aspects of child health vary according to the child's social background. ${ }^{1}$ These variations have been documented since the 19th century ${ }^{23}$ but interest in them has been rekindled within the last decade following the publication of the Black report into inequalities in health. ${ }^{45}$ It is of particular concern that the social variation is so consistent, with worse health occurring among children from poorer backgrounds, regardless of whether the measures of health are of physio- logical fitness, ${ }^{6}$ growth, ${ }^{7}$ psychological wellbeing ${ }^{8}$ or mortality and morbidity at any age, and for almost any medical disorder, ${ }^{14}$ or whether the measures of socioeconomic status are based on parental occupation, ${ }^{4}$ education, ${ }^{9}$ income,${ }^{10}$ marital state, ${ }^{11}$ employment status, ${ }^{12}$ or area deprivation characteristics. ${ }^{13}$ The extra burden of ill health borne by children from socially disadvantaged backgrounds is of such magnitude that it constitutes a major public health problem. The nature of these problems has long been appreciated by paediatricians ${ }^{14}$ but the extent of the problem is rarely measured at a local level, most of such studies being carried out on national data.

There are several pressing reasons why local studies are required: (a) the extent of local health inequalities is an important aspect of the monitoring of the health and health needs of children within a district; (b) the World Health Organisation 'Health For All' charter makes a reduction in inequalities one of its main objectives $^{15}$ - to implement this districts need to set targets and hence need to have a way of measuring inequalities; (c) districts need a means of monitoring the effects of interventions designed to reduce inequalities in child health within the district; (d) the results of national studies may not be applicable to a more localised district; and (e) the extent and causes of inequalities in child health are by no means agreed upon and further research into these questions is required. Finally, the development of information systems and the increasing power and accessibility of computer technology brings the measurement of local health inequalities within the grasp of most district based departments of child health or public health medicine.

Health inequalities are often measured using the Registrar General's classification of occupations, but there are many reasons why this is a poor method of social classification, ${ }^{16}$ particularly for women and children. ${ }^{17}$ Classification by the socioeconomic characteristics of the 'small area' of residence may be a valid alternative..$^{18}$ Social inequalities in health are measured by the difference in health between affluent and poor areas. These methods work particularly well in large urban areas, ${ }^{1920}$ but the greater social heterogeneity in more rural areas may blunt the measurement of health differences between the larger type of 'small area' such as wards. However, analysing smaller, and hence more homo- 
geneous, 'small areas' may help overcome this blunting effect. ${ }^{21}$

'Small area' methods using the smallest 'small area' possible, enumeration districts, are used in this study to measure inequalities in child health in a rural county in the north of England. By performing this study in a relatively rural health district, where the methodological problems resulting from social heterogeneity are likely to be most evident, it is intended to determine the wider applicability of these methods. The results measure the extent of social inequalities in aspects of child health and in the uptake of child health services which currently exist in Northumberland. The study acts as an example of the type of analyses possible using readily available data on child health.

\section{Methods \\ STUDY DISTRICT}

The study was carried out within Northumberland Health District. Northumberland is the northernmost county in England and has a total population of around 300000 . A variety of social and geographical conditions are represented in the county, with the south east corner consisting of a densely populated area of large and small towns, with a wide range of social conditions from deprived council estates of poor housing stock to affluent residential districts of high quality modern housing. The rest of the county is rural in character, but has a corresponding range of social conditions from small ex-mining villages and the poorer areas of the small rural towns, to the privileged commuter belt surrounding Tyneside.

\section{CHILD HEALTH DATA}

Health data were taken from two sources. From the district computerised child health records birth weight, maternal age at the child's birth, immunisation coverage, and child health surveillance screening coverage (at 6 weeks and 18 months of age) were available for all children resident in the district born between January 1985 and October 1990. The address of each child as recorded in October 1990 was used for the socioeconomic classification (see later). Health measures were defined as the proportion of live single births weighing less than $2800 \mathrm{~g}$, the proportion of births which were to mothers aged less than 20 years, the proportion of 15 month old children not fully immunised against pertussis, the proportion of inborn infants not screened at 6 weeks of age, and the proportion of 18 month old inborn children not screened at 18 months of age.

The denominators for each of these measures were different. Live single births was chosen as the denominator for the measure of birth weight because of the different distributions of birth weight of multiple births and stillbirths, both of which are recorded in the district child health records. The denominator for infants with teenage mothers was all births where this information was recorded. The denominator for pertussis immunisation was all children in the cohort who had reached 17 months of age by the time of analysis, to allow for the delay in reporting. This cohort was not affected by the change in immunisation schedule introduced in April 1990. The denominator for screening at 6 weeks of age was all resident, inborn children over 2 months of age born after June 1987, and the denominator for 18 month screening coverage was all resident, inborn children over 20 months age born after June 1987. Screening coverage was only recorded in Northumberland on the cohort of children born after this date and only inborn children were included because this was a locally agreed screening programme and children coming into the district from elsewhere would not have their screening history recorded.

The accuracy of the health data, particularly of immunisation and screening, was known to be high as a result of the local policy of feedback of named data back to primary health care. Various local evaluation studies have repeatedly shown that over $90 \%$ of this data is accurate (A F Colver, personal communication; R F Reading, unpublished observations).

The second source of health data was a survey of attained height of 5-8 year old schoolchildren. All local authority first schools in Northumberland were visited and children in year groups 1 , 2 , and 3 were measured by one of two trained research nurses using a Raven Karrimeter device. Height to the nearest millimetre, sex, age in days, and the postcode of the child's address were recorded. As each school was only visited once, absentees, comprising around $10 \%$ of children, were not measured. Although absentees may have had a different distribution of heights, this was not thought likely to influence the comparison between small areas which would only have been affected if different types of area had markedly different absence rates and the height of these absentees was markedly different from those present. The collection of data took seven months, therefore the age range represented was from $5 \cdot 0$ to 8.6 years.

The reproducibility of height measurements by the research nurses was tested on a sample of 95 children who were each measured twice by the two nurses, independently of each other. The mean difference in measurements between the nurses was $0.007 \mathrm{~cm}(95 \%$ confidence interval -0.059 to $0.073 \mathrm{~cm}$ ). Interobserver reliability of measurement was measured by the SD of the differences between the measurements of the two nurses. This was $0.464 \mathrm{~cm}$. Intraobserver reliability was measured by the $\mathrm{SD}$ of the difference between the two measurements of each nurse. For one of the nurses this was 0.387 $\mathrm{cm}$; for the other it was $0.454 \mathrm{~cm}$. Thus interobserver and intraobserver variability was around $0.4 \mathrm{~cm}$ - that is, $95 \%$ of measurements fell within $\pm 0.8 \mathrm{~cm}$ of each other, regardless of who performed them.

Heights were expressed as SD scores by subtracting each measurement from the mean height for that age and sex, and dividing by the SD for that age and sex. Mean and SD values of height by age and sex were derived from linear regression models using all the data collected for the study; in other words, by internal standardisation rather than by referring to any external reference values. Preliminary analysis showed 
Table 1 Variation in the rate of low birth weight, births to teenage mothers, pertussis immunisation, and screening coverage at 6 weeks and 18 months between the deciles of enumeration districts ranked by deprivation score. Values are percentage rates; values in parentheses are $95 \%$ confidence intervals of the rates

\begin{tabular}{|c|c|c|c|c|c|}
\hline $\begin{array}{l}\text { Decile of } \\
\text { enumeration } \\
\text { districts }\end{array}$ & $\begin{array}{l}\text { Birth weight }<2800 g \\
(\%)\end{array}$ & $\begin{array}{l}\text { Mother's age }<20 \\
\text { years (\% births) }\end{array}$ & $\begin{array}{l}\text { Pertussis } \\
\text { immunisation (\% not } \\
\text { immunised by } 15 \\
\text { months of age) }\end{array}$ & $\begin{array}{l}\text { Screening at } 6 \text { weeks } \\
(\% \text { not screened })\end{array}$ & $\begin{array}{l}\text { Screening at } 18 \\
\text { months }(\% \text { not } \\
\text { screened) }\end{array}$ \\
\hline $\begin{array}{l}1 \text { (deprived) } \\
2 \\
3 \\
4 \\
5 \\
6 \\
7 \\
8 \\
9 \\
10 \text { (affluent) }\end{array}$ & $\begin{array}{c}18.1(16.4 \text { to } 19 \cdot 8) \\
16.3(14.8 \text { to } 17 \cdot 8) \\
13.5(12.1 \text { to } 14.9) \\
14.0(12.3 \text { to } 15.6) \\
12.9(11.3 \text { to } 14.4) \\
11.4(10 \cdot 1 \text { to } 12.7) \\
9.9(8.5 \text { to } 11.3) \\
10.7(9.1 \text { to } 12.4) \\
11.0(9.5 \text { to } 12.6) \\
10.9(9.4 \text { to } 12.3)\end{array}$ & $\begin{array}{c}18.3(16.5 \text { to } 20.0) \\
14.9(13.4 \text { to } 16.5) \\
10.8(9.5 \text { to } 12 \cdot 1) \\
11.3(9.8 \text { to } 12.9) \\
10.2(8.8 \text { to } 11.7) \\
6 \cdot 1(5 \cdot 1 \text { to } 7.2) \\
6.6(5.4 \text { to } 7.9) \\
3.1(2.2 \text { to } 4.2) \\
2.6(1.9 \text { to } 3.6) \\
2.7(2.0 \text { to } 3.7)\end{array}$ & $\begin{array}{l}29 \cdot 3(27 \cdot 0 \text { to } 31.6) \\
25.4(23.4 \text { to } 27.5) \\
21.5(19.6 \text { to } 23 \cdot 4) \\
23.0(20.8 \text { to } 25 \cdot 2) \\
16.9(14.9 \text { to } 18 \cdot 8) \\
18.6(16.8 \text { to } 20.3) \\
20.8(18.7 \text { to } 22.9) \\
17.6(15.4 \text { to } 19 \cdot 8) \\
19.8(17.6 \text { to } 21.9) \\
18.7(16.7 \text { to } 20.6)\end{array}$ & $\begin{array}{l}6 \cdot 8(5 \cdot 3 \text { to } 8 \cdot 5) \\
9 \cdot 0(7 \cdot 4 \text { to } 10 \cdot 8) \\
6 \cdot 3(5 \cdot 0 \text { to } 7 \cdot 8) \\
8 \cdot 3(6 \cdot 5 \text { to } 10 \cdot 4) \\
6 \cdot 2(4 \cdot 7 \text { to } 7 \cdot 9) \\
7 \cdot 3(5 \cdot 8 \text { to } 9 \cdot 0) \\
6 \cdot 5(4 \cdot 9 \text { to } 8 \cdot 4) \\
5 \cdot 4(3 \cdot 9 \text { to } 7 \cdot 4) \\
4 \cdot 8(3.3 \text { to } 6 \cdot 6) \\
5 \cdot 0(3 \cdot 7 \text { to } 6 \cdot 6)\end{array}$ & $\begin{array}{l}21.0(17.4 \text { to } 24.7) \\
22 \cdot 0(18.7 \text { to } 25 \cdot 4) \\
14.3(11.3 \text { to } 17.2) \\
15 \cdot 1(11.5 \text { to } 18 \cdot 7) \\
16.5(13.1 \text { to } 19 \cdot 8) \\
16.7(13.5 \text { to } 19.9) \\
17.3(13.6 \text { to } 21 \cdot 0) \\
12.8(9.2 \text { to } 16 \cdot 4) \\
13.5(9.9 \text { to } 17 \cdot 0) \\
13.6(10.5 \text { to } 16.7)\end{array}$ \\
\hline Total & $13 \cdot 0$ & $9 \cdot 2$ & $21 \cdot 3$ & $6 \cdot 7$ & $16 \cdot 6$ \\
\hline $\begin{array}{l}\chi^{2} \text { Value } \\
\text { Degrees of freedom } \\
\text { p Value } \\
\chi^{2} \text { trend } \\
\text { p Value }\end{array}$ & $\begin{array}{l}108 \cdot 4 \\
9 \\
<0.001 \\
85.9 \\
<0.001\end{array}$ & $\begin{array}{l}531 \cdot 0 \\
9 \\
<0 \cdot 001 \\
493 \cdot 9 \\
<0.001\end{array}$ & $\begin{array}{c}122 \cdot 4 \\
9 \\
<0.001 \\
92 \cdot 9 \\
<0.001\end{array}$ & $\begin{array}{l}24 \cdot 6 \\
9 \\
<0 \cdot 01 \\
12 \cdot 2 \\
<0 \cdot 01\end{array}$ & $\begin{array}{l}31 \cdot 1 \\
9 \\
<0 \cdot 001 \\
16 \cdot 7 \\
<0 \cdot 001\end{array}$ \\
\hline
\end{tabular}

that linear equations of height by age fitted the data as well as any more complex equation. Further details of the standardisation procedure are available from the authors.

\section{SMALL AREA CLASSIFICATION}

Cases were allocated to their census enumeration district of residence using a standard geographical technique ${ }^{22}$ whereby the Ordnance Survey grid reference of the postcode is matched to the nearest enumeration district centroid grid reference. Enumeration districts are the smallest geographical unit for which census information is available and contain an average of 150 households, or 400 people. Enumeration districts were classified by the Townsend material deprivation index ${ }^{13}$ into deciles of roughly equal proportions of the population. These deciles ranged from the $10 \%$ of the population living in the most deprived areas to the $10 \%$ living in the most affluent areas. The Townsend material deprivation index for each enumeration district is derived from four census variables: the proportion of unemployed economically active adults; the proportion of households without the use of a car; the proportion of households not owner occupied; and the proportion of households with more than one person for each room. The unemployment and overcrowding variables are transformed logarithmically, then each variable is converted to $\mathrm{Z}$ score and the index is derived from the sum of these $\mathrm{Z}$ scores. A full description of the method of calculation is given in Townsend et al. ${ }^{13}$

Table 2 Variation in mean height between deciles of enumeration districts ranked by deprivation score

\begin{tabular}{llcl}
\hline $\begin{array}{l}\text { Decile of } \\
\begin{array}{l}\text { enumeration } \\
\text { district }\end{array}\end{array}$ & $\begin{array}{l}\text { Mean height } \\
(S D \text { scores) }\end{array}$ & $\begin{array}{l}\text { Noof } \\
\text { children }\end{array}$ & $\begin{array}{l}\text { 95\% Confidence } \\
\text { interval }\end{array}$ \\
\hline 1 (deprived) & -0.218 & 829 & -0.287 to -0.149 \\
2 & -0.104 & 1000 & -0.165 to -0.043 \\
3 & -0.075 & 1037 & -0.138 to -0.012 \\
4 & -0.089 & 787 & -0.160 to -0.018 \\
5 & 0.098 & 811 & $0 \cdot 027$ to 0.169 \\
6 & 0.020 & 1095 & -0.041 to 0.081 \\
7 & 0.057 & 814 & -0.010 to 0.124 \\
8 & 0.110 & 757 & 0.039 to 0.181 \\
9 & 0.041 & 868 & -0.024 to 0.106 \\
10 (affluent) & 0.094 & 1057 & 0.037 to 0.151 \\
\hline
\end{tabular}

\section{STATISTICAL ANALYSIS}

Statistical analyses were performed using the SPSSX statistical package. ${ }^{23}$ Rates of low birth weight $(<2800 \mathrm{~g})$, births to teenage mothers, pertussis immunisation coverage by 15 months, 6 week and 18 month screening coverage, and the mean height in SD scores were calculated for each decile of enumeration districts. Ninety five per cent confidence intervals of these rates and means have also been calculated. A measure of the significance of trends in rate with deprivation is shown by the $\chi^{2}$ test for trend.

\section{Results}

Data were available for 21702 children born between January 1985 and September 1990 from the district child health computer records. These children were recorded as resident in Northumberland at the time the data were drawn for analysis in October 1990. Data on height were available for 9930 children between 5.0 and

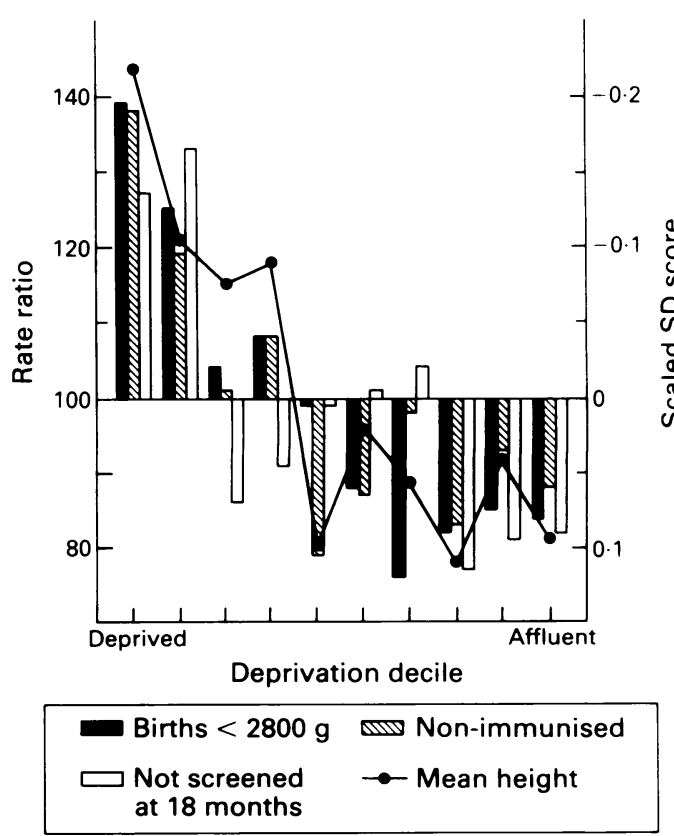

Figure 1 Comparison of pattern of health measures with deprivation using standardised rate ratios and scaled $S D$ scores. 
Table 3 Comparison of socioeconomic indicators between Northumberland, the Northern region, and England and Wales. Data from Office of Population Censuses and Surveys ${ }^{24}$

\begin{tabular}{lccc}
\hline & Northumberland & $\begin{array}{l}\text { Northern } \\
\text { region }\end{array}$ & $\begin{array}{l}\text { England } \\
\text { and Wales }\end{array}$ \\
\hline Economically active men unemployed (\%) & 9.6 & 16.2 & 11.6 \\
Economically active adults unemployed (\%) & 8.5 & 13.5 & 10.1 \\
Private households not owner occupied (\%) & 53.6 & 52.9 & 41.9 \\
Private households without use of car (\%) & 40.2 & 48.3 & 38.5 \\
Private households with more than one person in & 2.8 & 3.8 & 3.4 \\
\hline each room & 2.8 & & \\
\hline
\end{tabular}

8.6 years of age, although a small number of these children who attended Northumberland schools resided outwith the county and were therefore excluded from the analysis.

A small number of children $(<1 \%)$ had addresses which could not be postcoded. About $10 \%$ of postcodes could not be matched to an enumeration district using the computerised geographical matching method. Around $1 \%$ of those that were matched to an enumeration district could not be classified by a deprivation score because census information was restricted (that is, because the enumeration district was very small or included a military installation).

Numbers were further reduced by incomplete health data. Less than $5 \%$ of the children did not have a recorded birth weight, and slightly more than $5 \%$ did not have a recorded maternal age at birth.

None of these exclusions was felt to influence the results. More than $80 \%$ of children with eligible health data were included in the analyses, and of those children with no deprivation score (for whatever reason) the rates of low birth weight, births to teenage mothers, immunisation and screening coverage, and the mean height were all similar to the overall average for the whole cohort.

Table 1 shows the rates of low birth weight, births to teenage mothers, non-immunised 15 month old children, children who did not receive screening at 6 weeks of age, and children who did not receive 18 month screening between the different enumeration districts according to the deprivation score. Of the routine childhood immunisations only pertussis coverage is shown because the pattern of variation in coverage of the others was similar to that of pertussis.

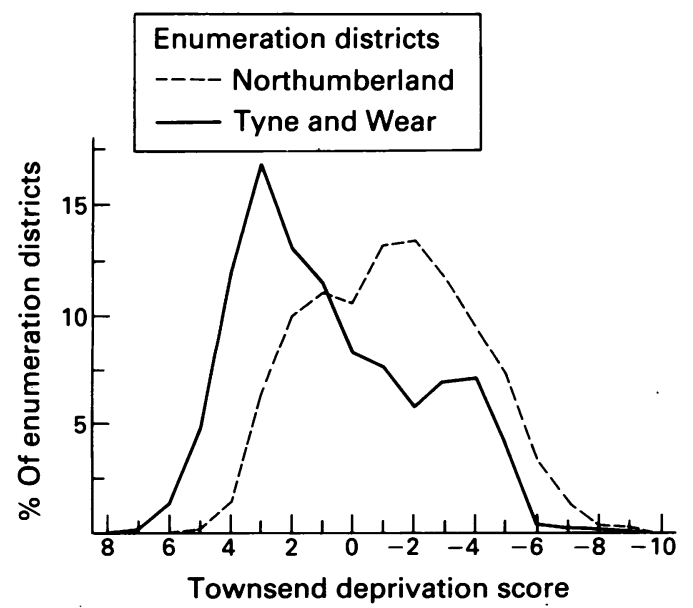

Figure 2 Distribution of deprivation scores of enumeration districts in Northumberland compared with Tyme and Wear.
Table 2 shows the mean height in SD scores between enumeration districts divided in the same way by deprivation score. For each of the measures there is a gradient between the most deprived decile of enumeration districts and the most affluent. The proportion of birth weights less than $2800 \mathrm{~g}$ ranged from 18 to $11 \%$ between the two extremes. Eighteen per cent of births in the most deprived areas were to teenage mothers compared with less than $3 \%$ in the most affluent. Pertussis immunisation coverage varied from 70 to $81 \%$, and 18 month screening coverage from 79 to $86 \%$. The mean height varied between -0.2 SD scores in the most deprived areas to +0.1 SD scores in the most affluent. Six week screening showed much less variation, however, coverage in all areas being over $90 \%$. Despite this, there were still slightly lower rates of coverage in the deprived areas compared with the affluent areas. In all instances the trend between deprived and affluent areas was statistically highly significant. Subtraction of the $\chi^{2}$ for trend value from the total $\chi^{2}$ value shows the residual variation not accounted for by deprivation. For low birth weight, teenage motherhood, and pertussis immunisation the residual variation is minimal compared with that due to deprivation. For the two measures of screening the residual variation was greater in proportion; however, the residual $\chi^{2}$ values are not significant in the case of 6 week screening $\left(\chi^{2}\right.$ $12 \cdot 4, \mathrm{df}=8, \mathrm{p}<0 \cdot 1)$ and only just significant for 18 month screening $\left(\chi^{2} 16 \cdot 4, \mathrm{df}=8, \mathrm{p}<0.05\right)$.

In addition to the gradient between deprived and affluent areas, another feature of the interarea variation is evident. For all the health measures apart from births to teenage mothers and 6 week screening coverage, most of the variation occurs among areas at the deprived end of the spectrum, with a plateau between the middle of the range of deprivation and the most affluent areas. This is illustrated in figure 1 where all the rates have been standardised by dividing by the overall average rate and multiplying by 100 , so that the average rate is equivalent to 100 . The SD scores for height have been inverted and scaled to give a comparable distribution. The pattern is most evident in the distribution of low birth weight, immunisation coverage, and mean height.

For these results to be compared with those found elsewhere, some comparative data on socioeconomic characteristics are required. Table 3 shows the four census variables used to derive the Townsend material deprivation index for Northumberland, the Northern region, and the whole of England and Wales. The proportions of the population living under conditions of social adversity in Northumberland are similar to the average for the whole of England and Wales, but less then for the rest of the Northern region.

Figure 2 shows the distribution of deprivation within Northumberland compared with that in Tyne and Wear. Tyne and Wear is a major conurbation consisting of Newcastle upon Tyne, North Tyneside, Gateshead, South Tyneside, and Sunderland. This figure shows enumeration districts at different levels of the Townsend material deprivation index. The distribution in 
Northumberland is skewed towards the affluent end of the spectrum, whereas the distribution in Tyne and Wear is skewed towards the deprived end. For comparison, the most deprived areas in Tyne and Wear are representative of the most deprived areas anywhere in England and Wales, ${ }^{13}$ although not in Scotland..$^{25}$ The most affluent areas in Northumberland and in Tyne and Wear are comparable with the most affluent areas found in many other parts of the country. ${ }^{20}$ Although the distribution of deprivation in Northumberland does not include areas with the highest concentration of multiple deprivation and poverty found in some of the northern conurbations, the range of socioeconomic characteristics represented is, nevertheless, wide and includes almost the whole range of deprivation found elsewhere apart from the aforementioned inner city areas.

\section{Discussion}

The two objectives of this study were to investigate the general applicability of small area methods in measuring child health inequalities at a district level and to contribute further evidence on the extent of inequalities in child health in contemporary Britain. For all measures of child health and use of child health services, apart from screening at 6 weeks of age, marked variations have been shown between deprived and affluent areas. Furthermore, these inequalities are shown within a health district which does not include any inner city areas with high concentrations of families living in poverty and multiple deprivation. An advantage of a local study such as this over regional or national studies is that the health variations shown are not influenced by large scale geographical influences, such as the association of latitude with mean height, ${ }^{26} 27$ nor by administrative differences in the provision of health or personal social services.

With respect to the first of these objectives, we have shown that small area methods of measuring child health inequalities do work. There are several reasons why social inequalities in health may still remain hidden. These include the misclassification of some postcodes to the wrong enumeration district ${ }^{28}$; the use of census data that is 10 years old to classify areas; and varying degrees of social heterogeneity, which is much greater in rural areas, wherein deprived families live alongside more affluent families, ${ }^{29}$ and, hence, the extent of material deprivation and ill health suffered by these families is submerged in the generally more favourable circumstances of the area as a whole.

All these problems tend to reduce the observed extent of health inequalities, but by how much is a matter for speculation. The choice of enumeration district as the geographical unit of analysis was made to minimise the blunting effects of social heterogeneity, but this had to be traded against an increase in the proportion of postcodes being mismatched to the incorrect enumeration district. We have carried out other studies which have shown that the effect of such mismatching is not as serious as might be expected, ${ }^{28}$ nevertheless, this alone might under- estimate area variations in social circumstances and health by as much as $25 \%$.

This geographical method of measuring social inequalities in child health can only be an approximation to the true extent of inequality. It is based on the transparently fallacious assumption that all families within a given small area share similar socioeconomic characteristics. Nevertheless, it is straightforward to perform, it shows social variations in child health measures as wide as those shown using other indicators of socioeconomic status such as occupational class, ${ }^{14-7}$ and it shows social variations in a mixed urban and rural district as wide as those found using ward based analyses in more built up urban areas. $^{13}$

These enumeration district based methods could be used to measure local social inequalities using a wide range of child health data. Examples of such data might be rates of breast feeding, smoking rates in parents of young children and in adolescents, rates of childhood respiratory illness, rates of iron deficiency in toddlers, and rates of emotional and behavioural disorders. The list could continue; the types of health problem worth studying in this way are those which are thought or known to vary according to social status, those which are important child health problems in terms of morbidity and numbers, and, ideally, those where preventable causes may be identified. The latter qualification is not strictly necessary because there is an argument that any health measure which varies with social status is potentially preventable by improving the social circumstances of those groups with the poorest health. ${ }^{4}$

With respect to the second objective, the results may be compared with those found in other studies, although no other study to our knowledge has used the same techniques on as wide a range of child health measures in a single health district. Low birth weight has been most studied. The range of area variations is similar to that found by Townsend $e t a l$ in a study of the whole of the Northern region,,$^{13}$ and further analysis of that data ${ }^{20}$ showed that the proportion of low birthweight infants found in the most deprived areas within the conurbations of the region $(17 \cdot 6 \%)$ is the same as we have found in the most deprived parts of Northumberland using enumeration districts as the unit of analysis. A study from Scotland used $2500 \mathrm{~g}$ as the cut off criterion for low birth weight and found a difference between the most deprived and affluent areas of 8.9 to $4 \cdot 2 \% .{ }^{30}$ Recalculating our data using this criterion gives a range from $7 \cdot 5$ to $5 \cdot 2 \%$ between the extreme two deciles, although the average rate of births less than $2500 \mathrm{~g}$ in deciles 6,7 , and 8 is $4.3 \%$, similar to the rate in the most affluent of the Scottish areas. Carstairs and Morris have argued that the poorer mortality figures in Scotland than in England and Wales are the result of a greater concentration of material deprivation in Scotland ${ }^{25}$; these results suggest a similar phenomenon for low birth weight.

Although the influence of social factors on height has been extensively studied, few studies have looked specifically at small area differences. Morgan and Chinn used data from the National 
Study of Health and Growth to calculate mean heights between areas differentiated by the ACORN classification. ${ }^{31}$ For those groups of areas where they had sufficiently large numbers, mean heights varied between -0.3 to $+0.2 \mathrm{SD}$ scores. They commented, however, that some of this difference was explained by the apparent association of latitude with mean height, therefore the range within a localised area such as a health district might be expected to be less.

There is little value in comparing variations in immunisation and screening coverage with studies from other districts because these are affected so much by local health authority and primary care related factors..$^{32}$ Nevertheless, the results for immunisation coverage reflect the general pattern of a modest but consistent difference in coverage between children from deprived and affluent backgrounds found elsewhere, ${ }^{33}$ whereas our results for screening coverage reflect the inconsistent variations seen in other studies, some even suggesting that coverage is better in more deprived areas. ${ }^{34}$ The universally high coverage of screening at 6 weeks of age in our study adds strength to the suggestion in the Hall report $^{35}$ that parents place a high value on this check, and further suggests that this high value extends throughout all social groups.

The reasons why local inequalities in health need to be measured were given in the introduction. This study has shown how 'small area' methods may be used in individual health districts as a means of monitoring social inequalities in commonly available indicators of child health and of child health service use. With the release of the 1991 census data for small areas this type of study will become much easier, more accurate, and more sophisticated analyses will be possible. It is therefore important to appreciate the scope of these studies and their potential drawbacks. By having this type of information it is likely that progress will be made in reducing social inequalities in child health.

The project was funded by Northumberland Health Authority. Mrs Pat Waugh and Miss Gwen Charlton performed the heigh survey. Dr Simon Raybould calculated the Townsend deprivation scores.

See related paper on $\mathrm{p} 686$

1 Blaxter M. The health of the children. London: Heinemann, 1981

2 Chadwick E. Report on an enquiry into the sanitary conditions of labouring populations of Great Britain. London: Poor Law Commission, HMSO, 1842.

3 Rowntree BS. Poverty. A study of town life. London: Macmillan, 1901.

4 DHSS. Inequalities in health: report of a research working group. London: DHSS, 1980. (Black report.)
5 Whitehead $M$. The health divide. In: Townsend $\mathrm{P}$, Davidson $\mathrm{N}$, Whitehead $\mathrm{M}$, eds. Inequalities in health. 2nd $\mathrm{Ed}$ Harmondsworth: Penguin, 1988.

6 Macintyre S. A review of the social patterning and significance of measures of height, weight, blood pressure and of measures of height, weight, blood pressure
respiratory function. Soc Sci Med 1988; 27: 327-37.

7 Tanner JM. Growth as a mirror of the conditions of society: secular trends and class distinctions. In: Demirian A, Brault Dubuc A, eds. Human growth: a multidisciplinary review. London: Taylor and Francis, 1986.

8 Graham PJ. Behaviour and intellectual development. $\mathrm{Br} \mathrm{Med}$ Bull 1986; 42: 155-62.

9 Power C, Manor O, Fox J. Health and class: the early years. London: Chapman and Hall, 1991.

10 Wilkinson RJ. Income and mortality. In: Wilkinson RJ, ed. Class and health: research and longitudinal data. London: Tavistock, 1986.

11 Gordon RR. Postneonatal mortality among illegitimate children registered by one or both parents. $B M \mathcal{F} 1990 ; 300$ : 236-7.

12 Rona RJ, Chinn S. National Study of Health and Growth: nutritional surveillance of primary school children from 1972 to 1981 with special reference to unemployment and social class. Ann Hum Biol 1984; 11 : 17-28.

13 Townsend $\mathrm{P}$, Phillimore $\mathrm{P}$, Beattie A. Health and deprivation: inequality and the north. London: Croom Helm, 1988.

14 Court SDM (chairman). Fit for the future. Report of the committee on child health services. London: HMSO, 1976.

15 World Health Organisation. Primary health care. Report on the international conference on primary health care: 1978 Sep 6-12; Alma-Ata, USSR. Geneva: WHO, 1978. (Health for all series No 1 .)

16 Jones IG, Cameron D. Social class analysis - an embarrassment to epidemiology. Community Medicine 1984; 6: 37-46.

17 Moser KA, Pugh HS, Goldblatt PO. Inequalities in women's health: looking at mortality differentials using an alternative approach. BMF 1988; 296: 1221-4

18 Carstairs V. Small area analysis and health service research Community Medicine 1981; 3: 131-9.

19 Thunhurst C. Analysis of small area statistics and planning for health. Statistician 1985; 34: 93-106.

20 Phillimore P, Reading R. A rural advantage: urban-rural health differences in northern England. $\mathcal{F}$ Public Health Med 1992; 14: 290-300.

21 Reading RF, Openshaw S, Jarvis SN. Measuring child health inequalities using aggregations of enumeration districts. F Public Health Med 1990; 12: 160-7.

22 Gatrell A, Dunn C, Boyle P. The relative utility of the central postcode directory and pinpoint address code in applications of geographical information systems. Environment and Planning (A) 1991; 23: 1447-58.

23 SPSS Inc. SPSSX users guide. 3rd Ed. Chicago: SPSS, 1988.

24 Office of Population Censuses and Surveys. Census 1981: county reports. London: HMSO, 1982.

25 Carstairs V, Morris R. Deprivation: explaining differences in mortality between Scotland and England and Wales. BMF 1989; 299: 886-9.

26 Foster JM, Chinn S, Rona RJ. The relation of height of primary school children to population density. Int $\mathcal{F}$ Epidemiol 1983; 12: 199-204.

27 Chinn S, Price CE, Rona RJ. Need for new reference curves for height. Arch Dis Child 1989; 64: 1545-53.

28 Reading $R$, Openshaw S. Do inaccuracies in small area deprivation analyses matter? F Epidemiol Community Health (In press).

29 Bradley T. Poverty and dependency in village England. In: Bradley T, Lowe P, Wright S, eds. Deprivation and welfare in rural areas. Norwich: GeoBooks, 1986.

30 Carstairs V, Morris R. Deprivation and health in Scotland. Aberdeen: Aberdeen University Press, 1991.

31 Morgan M, Chinn S. ACORN group, social class and child health. F E pidemiol Community Health 1983; 37: 196-203.

32 Jarman B, Bosanquet N, Rice P, Dollimore N, Leese B. Uptake of immunisation in district health authorities in England. BMF 1988; 296: 1775-8.

33 Peckham C, Bedford H, Senturia Y, Ades A. The Peckham report. National immunisation study: factors influencing immunisation uptake in childhood. London: Action Research for the Crippled Child, 1989.

34 While A. Child health clinic attendance during the first two years of life. Public Health 1990; 104: 141-6.

35 Hall DMB. Health for all children: a programme for child health surveillance: report of the joint working party on child health surveillance. Oxford: Oxford University Press, 1989. 